Proceedings

\title{
Lactose Malabsorption and Intolerance. The Role of Microbiota and Probiotics.
}

\author{
Rosaura Leis ${ }^{1,2,3}$ \\ 1 Centro de Investigación Biomédica en Red de Fisiopatología de la Obesidad y Nutrición (CIBEROBN), \\ Instituto de Salud Carlos III, Madrid, Spain. \\ 2 Unidad de Gastroenterología, Hepatología y Nutrición Pediátrica. Grupo de Investigación Nutrición \\ Pediátrica. Instituto de Investigación Sanitaria de Santiago de Compostela (IDIS). Complejo Hospitalario \\ Universitario de Santiago. Santiago de Compostela. Spain \\ 3 Unidad de Investigación en Nutrición, Crecimiento y Desarrollo Humano de Galicia (GALINUT), \\ Universidad de Santiago de Compostela, Santiago de Compostela, Spain.
}

Published: 30 October 2020

\begin{abstract}
Lactose intolerance (LI) is characterized by the presence of symptoms, mainly gastrointestinal, due to the colonic fermentation of lactose not absorbed by lactase enzyme deficiency. Lactase deficiency can be primary, congenital, or adult type lactase deficiency, and secondary to other pathologies that involve a loss of enzyme activity. The prevalence of adult type lactose malabsorption varies depending on ethnicity and geographic location. In Europe it is related to the presence of two single nucleotide polymorphisms (SNP C / T-13910 and G / A-22018). What is the best technique for its diagnosis, especially with what dose the provocation should be done and for how long it should be performed, is still under discussion. The clinical symptomatology in lactose intolerance is modified by the load of the lactose substrate, the activity of the lactase enzyme, the speed of intestinal transit, the rate of gastric emptying and colonic compensation. Some LI do not present symptoms after usual amounts of milk intake, mainly of yogurt and cheese. In addition, the intestinal microbiota will also modify the presence and severity of symptoms. So the modification of this with biotics could be a possibility of treatment and to promote dairy products consumption.
\end{abstract}

Publisher's Note: MDPI stays neutral with regard to jurisdictional claims in published maps and institutional affiliations.

(C) 2020 by the authors. Submitted for possible open access publication under the terms and conditions of the Creative Commons Attribution (CC BY) license (http://creativecommons.org/licenses/by/4.0/). 